\title{
HISTÓRIA DA SEXUALIDADE FEMININA NO BRASIL: ENTRE TABUS, MITOS E VERDADES
}

\author{
HISTORY OF FEMALE SEXUALITY IN BRAZIL: BETWEEN TABUS, MYTHS AND TRUTHS
}

\section{RESUMO}

$\mathrm{Na}$ atualidade as mulheres veem conquistando autonomia e independência, entretanto nem sempre foi assim, pois por muito tempo as mulheres foram ensinadas a oprimirem seus sentimentos, vontades e desejos. Nota-se que aconteceram diversas mudanças em relação à educação sexual das mesmas, despertando assim o interesse em melhor entender essa temática. Por conseguinte, o presente estudo tem por objetivo refletir sobre a história da sexualidade feminina no Brasil, suas transformações e evoluções em seu contexto social e cultural. O estudo é composto por pesquisa bibliográfica norteada em autores como, Aran (2003), Trindade e Ferreira (2008), Pedro (2003) dentre outros e pesquisa de campo, realizada por meio da aplicação de questionários com nove mulheres, entre acadêmicas e professoras de uma Universidade Federal de Mato Grosso do Sul. Ao final deste estudo, evidencia-se que a sexualidade feminina obedece a padrões próprios de determinadas épocas, sendo que por vezes as mulheres se veem obrigadas ter uma postura passiva e de castidade. Contudo, atualmente consegue-se discutir a sexualidade feminina de forma mais natural, porém, percebe-se que esta ainda está circundada por mitos e tabus. Apesar dos ideais de igualdade entre os sexos a sexualidade feminina ainda encontra-se historicamente repressiva.

Palavras-chave: Sexualidade feminina. Mitos. Cultura.

\begin{abstract}
Women are now seeing autonomy and independence, but this has not always been the case, for women have long been taught to oppress their feelings, wishes and desires. It is noted that there have been several changes in relation to their sexual education, thus arousing interest in better understanding this theme. Therefore, the present study aims to reflect on the history of female sexuality in Brazil, its transformations and evolutions in its social and cultural context. The study is composed of bibliographical research guided by authors such as Aran (2003), Trindade and Ferreira (2008), Pedro (2003) among others and field research, carried out through the application of questionnaires with nine women, between academics and teachers of a Federal University of Mato Grosso do Sul. At the end of this study, it is evident that female sexuality obeys the patterns of certain epochs, and sometimes women are forced to have a passive and chastity. However, it is now possible to
\end{abstract}

Edicleia Lima de Oliveira

Universidade Federal de Mato Grosso do Sul. E-mail: edicleia.oli1@gmail.com

Jaqueline Martins Rezende

Universidade Federal de Mato Grosso do Sul. E-mail: jmr_@live.com.pt

Josiane Peres Gonçalves

Universidade Federal de Mato Grosso do Sul. E-mail: josianeperes7@hotmail.com 
discuss female sexuality in a more natural way, but it is perceived that it is still surrounded by myths and taboos. In spite of the ideals of equality between the sexes the feminine sexuality still finds itself historically repressive.

Keywords: Female sexuality. Myths. Culture.

\section{Introdução}

A presente pesquisa apresenta alguns discursos sobre a sexualidade feminina que durante séculos foi entendida como algo inexistente, pois a mulher era vista apenas como reprodutora. Atualmente, essa temática está conquistando espaço na sociedade e vem se apresentando como algo que deve ser exposto e dialogado; porém, nota-se que falar sobre esses assuntos ainda rende muitos tabus, fazendo com que inúmeras mulheres não consigam conversar a respeito. Esse fenômeno, consequentemente, restringe as mulheres com relação à exploração e valorização dos seus desejos. Portanto, este tema deve ser tratado de forma a propiciar o conhecimento acerca das questões que circundam em torno da sexualidade feminina, na busca por romper padrões e conceitos errôneos.

Sendo assim, por meio de estudos teóricos, no decorrer do presente estudo busca-se compreender a história da sexualidade feminina no Brasil e as influências exercidas pelo contexto cultural, social e familiar. A pesquisa de campo foi realizada por meio de questionários que foram respondidos por mulheres com idades distintas, que relataram sobre algumas de suas experiências sexuais. Portanto, com esse estudo espera-se refletir sobre como a mulher compreende sua sexualidade, quais os avanços, retrocessos, tabus e verdades sobre essa temática.

\section{A trajetória da sexualidade feminina no contexto brasileiro}

Sexualidade, corpo e gênero são temas que causam muitas dúvidas, polêmicas e inquietações; o que torna essencial a discussão sobre tais assuntos, a fim de entender como esses aspectos influenciam a vida e o cotidiano das pessoas. Sobre esse assunto, Louro (2008, p. 2), declara que:

A construção do gênero e da sexualidade dá-se ao longo de toda a vida, continuamente, infindavelmente. Quem tem a primazia nesse processo? Que instâncias e espaços sociais têm o poder de decidir e inscrever em nossos corpos as marcas e as normas que devem ser seguidas? Qualquer resposta cabal e definitiva a tais questões será ingênua e inadequada. A construção dos gêneros e das sexualidades dá-se através de inúmeras aprendizagens e práticas, insinua-se nas mais distintas situações, é empreendida de modo explícito ou dissimulado por um conjunto inesgotável de instâncias sociais e culturais. 
Além desses aspectos, deve-se levar em consideração que a sociedade impõe padrões sociais, comportamentais e sexuais, sendo que esse "É um processo minucioso, sutil, sempre inacabado. Família, escola, igreja, instituições legais e médicas mantêmse, por certo, como instâncias importantes nesse processo constitutivo" (LOURO, 2008, p. 2).

Esses "padrões sociais" se refletem na história da sexualidade feminina, que mais especificamente no Brasil, passou por grandes transformações no decorrer do tempo até chegar ao modelo que se vê nos dias atuais. Certo é que essa temática é circundada por grandes debates, cheios de mitos, tabus e verdades. Nesse sentido, Zican (2005, p. 8) afirma que "Até o final do século XIX as mulheres saudáveis eram as que não tinham desejos sexuais, esperava-se da mulher o não prazer". Nesse contexto, o sexo no matrimônio tinha como finalidade a reprodução humana, e quando um homem buscava por um casamento, a escolha era por mulheres reprodutoras, enquanto as mulheres mais erotizadas eram tidas por amantes.

A mulher, pela sua condição desigual em relação ao homem, por muitos anos viveu sob a sua tutela, em primeira instância do pai e em segunda do marido, com sua sexualidade normatizada pelos padrões Cristãos, legitimada pela instituição do casamento e pelo cumprimento da função reprodutora (TRINDADE; FERREIRA, 2008, p. 418).

Dessa forma, a vida sexual das mulheres, no decorrer da história, esteve embasada em padrões morais, éticos, comportamentais, entre outros, que ensinavam as mulheres para viver em família, a zelar pelo lar, sendo encarregadas de cuidar da casa e dos filhos.

Sob essa ótica, Del Priore (2004), salienta que a igreja tinha grande influência sobre a sexualidade feminina, visto que esta apregoava que as mulheres deveriam ter seus desejos desde muito cedo abafados e reprimidos, para que assim elas não caíssem em tentação como aconteceu com Eva no jardim do éden. Desse modo, após terem seus desejos domados, as mulheres se tornavam aptas para o matrimonio, sendo que este, por vezes, era com homens bem mais velhos. Assim a autora explana que "Finalmente, com prazer ou sem prazer, com paixão ou sem paixão, a menina tornava-se mãe, e mãe honrada, criada na casa dos pais, casada na igreja. Na visão da sociedade misógina, a maternidade teria de ser o ápice da vida da mulher" (DEL PRIORE, 2004, p. 43).

Verifica-se que a igreja fomentava a ideia de a mulher ser submissa e não ter poder sobre seu próprio corpo; nota-se, ainda, que este discurso influenciou no desenvolvimento da sexualidade feminina, pois as mulheres que não se encaixavam nas normas da igreja não eram tidas como honestas e, assim, não eram para casar. Conforme analisam Morga e Lage (2015, p. 164): 
[...] O mundo feminino passa pela história da humanidade como um lugar a ser vigiado e punido. Condenada ao degredo de pecados silenciosos, contidas confissões de corações entristecidos e olhares melancólicos, a mulher se vê entre o labirinto do pudor e os prazeres que lhe são negados. Filhas do medo, mães do silêncio, esposas do recato, mulheres do mundo feérico.

Observa-se que durante séculos, o sexo para as mulheres era tido somente como forma de reprodução, não restando a elas outra função para o ato, sendo que grande parte nem se dava conta do quanto isso a afetava, dessa maneira muitas mulheres culpavam-se por coisas que deveriam ser completamente normais. Todavia, é oportuno destacar que houve uma grande mudança nesse contexto com a entrada da mulher no mercado de trabalho, pois elas continuaram a conquistar lugares nos espaços públicos, o que proporcionou questionamentos, reflexões e acesso a trocas de experiências que culminaram em transformações radicais e positivas.

O grande marco da mulher ocorreu após as $1^{\underline{a}}$ e $2^{\underline{\underline{a}}}$ Guerras Mundiais, onde ela teve que sair de casa para começar a trabalhar nas indústrias. Neste período os homens estavam lutando e também muitas mulheres ficaram viúvas, a única maneira de obter o sustento de casa foi buscar espaço no mercado de trabalho. A partir deste momento então, houve uma grande mudança no mundo feminino. A mulher passa dos muros da casa e vai buscar fora a sua independência. Na década de 6o, com a chegada da pílula anticoncepcional ela passa a separar sexo produtivo do sexo prazeroso (ZICAN, 2005, p. 8).

Nessa perspectiva, a pílula anticoncepcional representou um grande avanço para o público feminino, "Muitas iniciavam o uso desta medicação um mês antes do casamento. Pode-se, portanto, afirmar que na década de sessenta, meios seguros de contracepção eram buscados pelas mulheres". Isso permitiu com que as mulheres controlassem a questão da natalidade e também deixassem de ser vistas somente como reprodutoras, passando a separar a reprodução do prazer (PEDRO, 2003, p. 248).

Vale ressalvar que com a revolução industrial as mulheres conquistaram mais espaços e, dessa maneira, começaram a adquirir independência e autonomia, fato este que ocasionou mudanças nos papeis sociais para homens e mulheres. Aran (2003) enfatiza que a entrada da mulher no mercado trabalhista proporcionou que elas tivessem maior compreensão quanto aos seus direitos e, assim, buscassem a "liberdade" e o prazer sexual almejado, tendo clareza de que a sexualidade não se baseia apenas na reprodução. Observa-se que a partir de então a mulher começou a optar por experiências da atividade sexual de outras formas, buscando alcançar satisfação e prazer. 


\section{As mulheres e seu novo papel em relação à sexualidade}

Trindade e Ferreira (2008) ponderam que as mulheres vêm conquistando cada vez mais espaços na sociedade; no entanto, mesmo vivendo com maior liberdade, muitas delas ainda se sentem responsabilizadas por todos os problemas relativos ao sexo, e geralmente são passivas e submissas aos desejos dos parceiros. Verifica-se que existe uma construção cultural de que as mulheres devem satisfazer o marido ou namorado mantendo assim relações sexuais, por vezes, sem vontade. Cansadas, satisfazem seus parceiros sem satisfazer a elas mesmas ou inventam "desculpas" para evitar a relação.

Tais referências conduzem a ideia de Nogueira (2016), que aborda sobre a falta de conhecimento em relação ao próprio corpo e se apresenta como uma das barreiras cruciais que impede muitas mulheres de alcançar a plenitude sexual, haja vista que desde pequenas são educadas para não conhecer nem olhar seu corpo, pois tal comportamento é compreendido como errado e feio. Nota-se que a sexualidade influencia pensamentos, sentimentos e ações, por conseguinte mantem o equilíbrio, a saúde física e mental. Sendo assim, o orgasmo é um indicador de bem estar para ambos os sexos.

Segundo as análises de Fonseca (2011, p. 224),

As conquistas da mulher ao longo do tempo nos permite dizer que todas as formas de prazer são permitidas; logo, o sexo e a sexualidade da mulher dizem respeito a si própria, ela é quem deve determinar regras, normas, o lícito e o ilícito. Considerando as relações de poder e as construções socioculturais sobre as posturas sobre o sexo e a sexualidade da mulher, haverá sempre as diferenças e discórdias que dividiram os atores sociais (p. 224).

Nesse sentido, é possível inferir que a sexualidade feminina é uma temática ampla, com distintas ramificações e algumas problemáticas no âmbito sociocultural. Entretanto, é imprescindível que as experiências e vivências da sexualidade feminina sejam sempre fontes de bem estar e prazer para elas e para com aqueles que compartilham. Assim, acredita-se que essa temática precisa ser discutida de forma natural na família e na escola para possibilitar explicações acerca da sexualidade feminina além dos órgãos reprodutores.

Constata-se no decorrer desta pesquisa que apesar das mulheres terem conquistado autonomia, ainda existe certo "receio" acerca da sexualidade feminina para a busca de satisfação sem culpa, pois aspectos sociais, religiosos e culturais continuam intermediando esta relação, acarretando bloqueios para um desempenho satisfatório sem culpa ou obrigação. Por conseguinte, o presente estudo tem por objetivo refletir sobrea história da sexualidade feminina no Brasil, suas transformações e evoluções em seu contexto social e cultural. 


\section{Metodologia}

O presente estudo se configura como uma pesquisa de natureza quanti/ qualitativa, sendo que, "Do ponto de vista metodológico, podemos identificar trabalhos que evidenciam a necessidade dos estudos quantitativos complementados por estudos qualitativos, com o objetivo de aumentar a validade de seus constructos" (KIRSCHBAUM, 2013, p. 181).

Sob essa égide, inicialmente foram realizados estudos sobre a abordagem teórica e possibilidades para a efetivação da pesquisa de campo. Para o desenvolvimento da coleta de dados, optamos pela utilização de questionários, pois esses se apresentam eficazes ao considerarmos o questionário "[...] como a técnica de investigação composta por um número mais ou menos elevado de questões apresentadas por escrito às pessoas, tendo por objetivo o conhecimento de opiniões, crenças, sentimentos, interesses, expectativas, situações vivenciadas etc." (GIL, 1999, p. 128).

As questões foram objetivas e subjetivas sobre alguns aspectos da vida sexual. Participaram do estudo um total de nove mulheres com idade entre 19 e 46 anos. É oportuno destacar que a pesquisa foi realizada com estudantes e professoras de uma unidade da Universidade Federal de Mato Grosso do Sul (UFMS).

Vale salientar que para melhor abranger o perfil das participantes da pesquisa, foi elaborado um quadro que delibera algumas informações da coleta de dados. Para preservação da identidade das envolvidas, foram utilizadas identificações fictícias. Dessa forma, contamos com as seguintes participantes:

Quadro 1- Perfil e algumas características sexuais das participantes

\begin{tabular}{|c|c|c|c|c|}
\hline Identificação & Idade & $\begin{array}{c}\text { Estado } \\
\text { Civil }\end{array}$ & $\begin{array}{c}\text { Perdeu a } \\
\text { virgindade }\end{array}$ & $\begin{array}{c}\text { Casou } \\
\text { virgem }\end{array}$ \\
\hline MI- Aluna do curso de Pedagogia & 19 anos & Solteira & Entre 17 a 24 anos & - \\
\hline M2- Aluna do curso de Ciências Sociais & 21 anos & Solteira & Entre 17 a 24 anos & - \\
\hline M3- Aluna do Curso de Administração & 22 anos & Solteira & É virgem & - \\
\hline M4- Aluna do Curso de Pedagogia & 22 anos & Solteira & Entre 15 a 17 anos & - \\
\hline M5- Aluna do Curso de Pedagogia & 26 anos & Solteira & Entre 15 a 17 anos & - \\
\hline M6- Aluna do curso de Pedagogia & 33 anos & Casada & Entre 15 a 17 anos & - \\
\hline M7- Aluna do curso de Pedagogia & 36 anos & Casada & Entre 15 a 17 anos & Não \\
\hline M8- Professora do curso de Pedagogia & 40 anos & Casada & Entre 17 a 24 anos & Não \\
\hline M9- Professora do curso de Pedagogia & 46 anos & Casada & Entre 17 a 24 anos & Não \\
\hline
\end{tabular}

Fonte: Autoras (2018).

\section{Resultados e discussões}

Para dar início às discussões, a seguir apresenta-se um gráfico sobre algumas questões referentes a fatos sexuais vivenciados pelas participantes da pesquisa. 
Gráfico 1 - Vivências sexuais das participantes da pesquisa

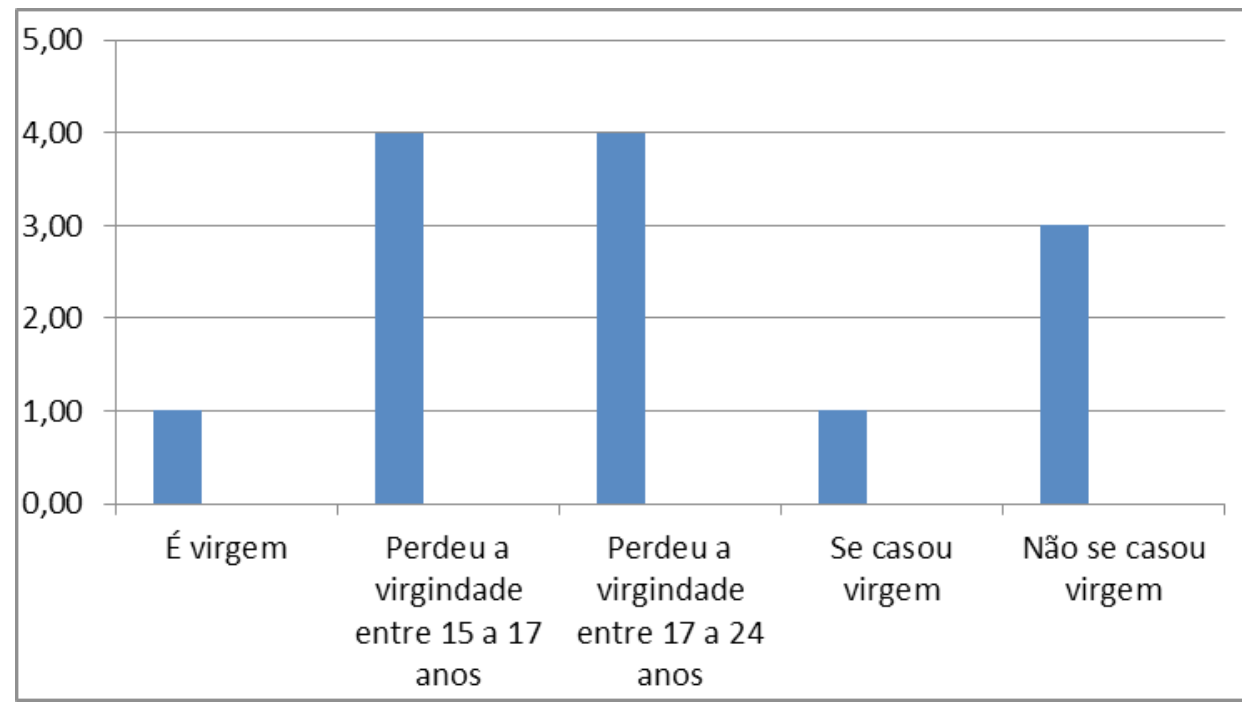

Fonte: Autoras (2018)

Por meio da análise do gráfico e das informações gerais, fica evidente que as participantes perderam a virgindade entre 15 e 24 anos, levando em consideração que dentre um total de nove mulheres, somente quatro são casadas e duas são virgens. Sendo assim, é perceptível que a maioria das mulheres, independente da idade, manteve relações sexuais antes do casamento. Esse fato pode ser considerado como gerador de grandes discussões, pois tem-se a ideia de que perder a virgindade antes do casamento é algo muito recente, sendo essa uma consequência da modernidade. No entanto, tal fato não foi evidenciado nos resultados, tendo em vista que a participante mais velha, com quarenta e seis anos, não casou virgem.

Essa aparente liberdade de escolha por perder ou não a virgindade antes do casamento não aconteceu por acaso, uma vez que tem sido algo conquistado através de movimentos sociais, em especial por parte do movimento feminista, o que proporcionou e ainda proporciona à mulher uma nova forma de viver sua sexualidade. Sobre essa perspectiva, em uma pesquisa cuja temática abordava adolescência e relações amorosas, realizada por Matos, Carneiro e Jablonski (2005), com adolescentes entre 13 e 17 anos, constatou- se que:

Os sujeitos mostraram concordar com a ideia sobre virgindade originada com o movimento feminista, iniciado no século XIX, em que a mulher não precisaria mais ser virgem para casar, gozando de uma sexualidade mais livre e espontânea, inclusive vendo como possível, em alguns casos, a maternidade fora do casamento (p. 27).

Sendo assim, hoje em dia é possível evidenciar uma nova percepção a cerca da virgindade e da sexualidade feminina. Porém, é importante destacar que os conceitos e valores postos sobre a virgindade da mulher variam de cultura para cultura e, considerando 
que o Brasil é composto por uma grande variedade de culturas, é evidente que cada uma age de acordo com as suas representações sociais. Nesse sentido, Ressel e Gualda (2003, p. 4), ao realizarem uma pesquisa com mulheres do campo sobre questões de sexualidade, afirmam que:

Foi percebido, neste estudo, que as mulheres aceitavam o mito da virgindade feminina e o valorizavam, atribuindo-lhe um significado de "valor, objeto de troca, honra". Consideravam tal mito como um "selo de garantia", sendo assim imperativa sua preservação até o casamento. Entendiam a relação sexual como um compromisso no casamento, portanto, só neste contexto permitida.

Entre as questões dissertativas do questionário, foi perguntado às participantes do estudo se elas tiveram no decorrer da vida alguma informação sobre relação sexual e como se deu esse processo, no entanto, entre as nove participantes, apenas a $\mathrm{M}_{3}$ relata que teve e tem um diálogo aberto com sua mãe acerca de sexualidade. Acredita-se que esta ocorrência se dá pelo fato de ela vir de uma geração mais nova e com uma mentalidade um pouco mais aberta em relação a estas questões. Entretanto, as demais participantes que também se encontram na mesma faixa etária que $\mathrm{M}_{3}$ relatam que não tiveram nenhum tipo de orientação quanto aos assuntos ligados à sexualidade, evidenciando uma questão de tabu cultural em relação a esta temática, transparecendo, assim, a dificuldade que a sociedade ainda tem em tratar a sexualidade feminina como algo natural, inerente a natureza humana. Nesse seguimento, Ressel et al. (2011, p. 247) pondera que:

\begin{abstract}
Quando os pais não reconhecem o amadurecimento da sexualidade de suas filhas, desperdiçam a oportunidade de proporcionar espaços para a discussão sobre suas vivências e o esclarecimento de dúvidas. Além disso, falar com censura ou ser indiferente à sexualidade pode potencializar uma prática sexual insegura, desprovida de orientações ou baseada em informações inadequadas.
\end{abstract}

Na sequência, foi questionado às participantes, se durante o ato sexual elas priorizam o prazer próprio ou o prazer do parceiro ,e sobre esse aspecto, a maioria das participantes salientou que durante a relação sexual o prazer deve ser próprio ou mútuo. Entretanto, três das entrevistadas disseram que optam pela satisfação do parceiro. Desse modo, verifica-se neste pensamento que algumas mulheres continuam nutrindo tabus de que devem sempre satisfazer os parceiros, deixando de vivenciar o sexo como fonte de prazer próprio. Por outro lado, para os homens esse fato é visto como normal, pois por vezes eles apenas satisfazem a si mesmos. Segundo Dos Santos et al. (2014, p. 117), “[...] a mulher constrói suas vivências a partir 
dos aspectos subjetivados culturalmente, em que o papel feminino tem sido restrito a satisfazer o companheiro e a reproduzir, reprimindo o seu desejo sexual".

Para finalizar, foi inquirido sobre questões referentes à masturbação feminina, explicitando se eram contra ou a favor e se já haviam praticado. Nesse sentido, a M1 diz que "Nunca pratiquei. Mas essa é a melhor forma de a mulher conhecer o seu corpo”. De maneira análoga, M3 e M8 argumentam que essa prática é normal, porém nunca praticaram. Sobre esse aspecto, as outras participantes relatam que:

Sim. Penso que é normal, pois da mesma forma que o homem tem a possibilidade de se obter prazer, dessa forma é justo a mulher poder também (M2).

Acho bastante normal, pois nós mulheres precisamos ter o conhecimento de nosso próprio corpo $\left(\mathrm{M}_{4}\right)$.

Sim, penso ser uma prática positiva para o conhecimento do próprio corpo $\left(\mathrm{M}_{5}\right)$.

Faz parte da natureza humana sentir desejos, porém, se isso é prejudicial se torna uma agressão contra o próprio corpo (M6).

Tudo de bom e pratico frequentemente. É a melhor forma de você se conhecer e conseguir chegar ao orgasmo mais facilmente $\left(\mathrm{M}_{7}\right)$.

Sobre essa mesma questão, M9 relata nunca ter praticado e, além disso, ela não concorda e não gosta desse ato. Em sua pesquisa de mestrado, Sérgio Werner Baumel (2014) se propôs a investigar o papel da masturbação na vida da mulher, discorrendo sobre como o entendimento da masturbação feminina se sucedeu no decorrer da história. Segundo o autor, esse era visto como um ato imoral, pecaminoso e as mulheres desde pequenas eram ensinadas a não praticar, elas eram intimidadas por ameaças de que isso lhes causaria dano físico e psicológico.

Com o passar dos tempos essas conspecções foram se modificando, pois assim como Baumel (2014) afirma, "O conhecimento do corpo e de suas sensações pode ter influência direta no desejo sexual, na capacidade de excitação e de obtenção de prazer e, em última instância, na própria satisfação sexual” (p. 26). Assim sendo, o ato de se masturbar pode proporcionar à mulher benefícios em diversos aspectos, principalmente em relação a sua saúde sexual.

[...] as mulheres que se masturbam, conhecendo melhor, portanto, o próprio corpo, tendem a não valorizar os valores tradicionais e estigmas ligados à ideia de promiscuidade, permitindo-se uma maior quantidade de experiências sexuais diferentes (BAUMEL, 2014, p. 26). 
Ainda sobre esse aspecto, ao concluir sua pesquisa, Baumel (2014) declara:

Amasturbação, emespecial, apesardeseralgoque, aparentemente, só deveria dizer respeito a cada indivíduo, ainda sofre os efeitos da posição de pecado e de geradora de doenças em que foi colocada durante séculos. Além disso, a sexualidade feminina vem sofrendo maiores repressões do que a masculina ao longo da história, ao se manter um duplo padrão de moral, mais restritivo para as mulheres e mais condescendente para os homens (p. 115).

É oportuno enfatizar que falar sobre sexualidade feminina é algo que ainda gera muitas polêmicas, principalmente no que se refere à masturbação, virgindade e submissão. Isso se deve ao fato de que historicamente as mulheres tiveram seu prazer no ato sexual negado ou esquecido, tendo como foco principal proporcionar o prazer aos seus parceiros ou como fonte reprodutora. Por meio dos relatos das participantes é possível notar um grupo de mulheres bem resolvidas em relação ao assunto aqui discutido, que ainda se mostra tão polêmico nos dias atuais.

Os resultados do Estudo I apontam para a existência de um processo de transição das Representações Sociais identificadas, abandonando os conceitos tradicionais ligados aos tabus e aos valores de duplo padrão de moral, aproximando essas Representações Sociais dos conceitos sustentados pelas áreas das ciências da saúde voltadas para a sexualidade, que defendem a masturbação como parte saudável da sexualidade, em qualquer época ou situação da vida. Essa transição mostra-se mais evidente entre as mulheres do que entre os homens, que mantêm de modo mais intenso representações ligadas às ideias tradicionais (BAUMEL, 2014, p. 107).

Observa-se, assim, que mesmos historicamente sejam consideradas recentes as discussões sobre a sexualidade feminina, muitas mulheres vem se preocupando com o corpo e com seu prazer sexual. Mesmo assim, algumas continuam a pensar que tocar o próprio corpo, com a finalidade de se conhecer e sentir prazer, é uma prática inadequada e que não deve ser reproduzida.

\section{Considerações Finais}

Tendo em vista que este estudo teve por objetivo refletir sobre a história da sexualidade feminina no Brasil, mediante a pesquisa bibliográfica realizada, é perceptível que a sexualidade feminina passou por transformações e evoluções que proporcionaram liberdade sexual para as mulheres ao longo da historia. Atualmente esta temática ainda fomenta questionamentos, pois a sexualidade evolui e molda- 
se conforme as concepções culturais e sociais. Entretanto, ainda existem mitos e preconceitos no desenvolvimento da sexualidade feminina. Nota-se que predominam os padrões subjacentes de independência sexual e, dessa maneira, a busca pela satisfação e prazer sexual por vezes está muito longe de se consumar para muitas mulheres.

Acredita-se que é necessário que as mulheres tenham pleno desenvolvimento de suas vontades, desejos, comportamentos sexuais, e, sobretudo, clareza de que os aspectos culturais e tabus que permeiam este tema não devem persuadi-las na reflexão da sua identidade sexual e conhecimento do seu corpo, para que assim elas tenham um desempenho sexual satisfatório, percebendo a sexualidade como algo natural e prazeroso. No entanto, ainda é necessário um longo caminho para que a sexualidade feminina seja expressa de forma natural, tendo em vista que essa é cercada de conceitos morais, culturais e sociais.

\section{REFERÊNCIAS}

ARAN, Márcia. Os destinos da diferença sexual na cultura contemporânea. Rev. Estud. Fem. Florianópolis, v. 11, n. 2, p.399-422. ISSN 0104-026X. 2003. Disponível em < http://www.scielo.br/scielo.php?pid=So104-026X2003000200004\&script=sci abstract\&tlng=pt $>$ Acesso em: 20 nov. 2017.

BAUMEL, Sérgio Werner. INVESTIGANDO O PAPEL DA MASTURBAÇÃO NA SEXUALIDADE DA MULHER. 2014. 144f. Dissertação (Mestrado em Psicologia)Universidade Federal do Espírito Santo- Centro de Ciências Humanas e NaturaisDepartamento de Psicologia Social e do Desenvolvimento, Vitória, 2014.

DEL PRIORE, Mary. História das Mulheres no Brasil. 7. ed. São Paulo: Contexto, 2004 .

FONSECA, Maria Elizabeth Melo da. Religião, Mulher, Sexo e Sexualidade: que discurso é esse?. Paralellus, Recife, Ano 2, n.4, jul./dez. 2011, p. 213-226. ISSN: 21788162.

GIL, Antônio Carlos. Métodos e técnicas de pesquisa social. 5. ed. São Paulo: Atlas, 1999 .

KIRSCHBAUM, Charles. Decisões entre pesquisas quali e quanti sob a perspectiva de mecanismos causais. Revista Brasileira de Ciências Sociais. Vol. $28 \mathrm{~N}^{\circ} 82$, junho/2013, p. 159 a 257.

LOURO, Guacira Lopes. Gênero e sexualidade: pedagogias contemporâneas. ProPosições. v. 19, n. 2 (56), maio./ago. 2008, p 17-23. 
MATOS, Mariana; CARNEIRO, Terezinha Féres; JABLONSKI, Bernardo. Adolescência e relações amorosas: um estudo sobre jovens das camadas populares cariocas. Interação em Psicologia, 2005, 9(1), p. 21-33.

MORGA, Antônio Emilio; LAGE, Mônica Maria Lopes. Sedução, Intriga e Entrega nos Seringais do Amazonas: Francisca Ribeiro e Antonio Alves da Cunha. Disponível em: <http://filo.unt.edu.ar/wp-content/uploads/2015/11/t11_9_morga. pdf>. Acesso em: 12 jul. 2018.

NOGUEIRA, Luanda. Mitos e Tabus sobre a sexualidade feminina. Revista digital Sociedade Pública. Disponível em: <http://sociedadepublica.com.br/mitos-etabus-sobre-a-sexualidade-feminina/>. Acesso em: 15 nov. 2017.

PEDRO, Joana Maria. A experiência com contraceptivos no Brasil: uma questão de geração Revista Brasileira de História. São Paulo, v. 23, no 45, p. 239-26o - 2003.

RESSEL, Lúcia Beatriz; GUALDA, Dulce Maria Rosa. A sexualidade como uma construção cultural: reflexões sobre preconceitos e mitos inerentes a um grupo de mulheres rurais. Revista da Escola de Enfermagem da USP . São Paulo. 2003; 37(3): 82-7, p. 82-87.

TRINDADE, Wânia Ribeiro; FERREIRA, Márcia de Assunção. Sexualidade feminina: questões do cotidiano das mulheres. Texto Contexto Enferm, Florianópolis, 2008 Jul-Set; 17(3): 417-26.

ZIKAN, Idalina da Silva. O Prazer Sexual Feminino na História Ocidental da Sexualidade Humana. Universidade Cândido Mendes (Monografia), 2005, 95 f. Disponível em: <http://www.avm.edu.br/monopdf/3/IDALINA\%2oDA\%2o SILVA\%2oZIKAN.pdf.> Acesso em: 15 nov.2017.

Recebido: 25.11.2017

Aceito: 10.10.2018 